\title{
The Choice of Multimodal Transport Mode of Agricultural By- Product Logistics in Land-Sea New Corridor in Western China Based on Big Data
}

\author{
Xing Chen ${ }^{1}$ and Ziyu Liu $\mathbb{D}^{2}$ \\ ${ }^{1}$ Department of Business Administration, Honam University, \#120 Honamdae-gil, Gwangsan-gu, \\ 62399 Gwangju, Republic of Korea \\ ${ }^{2}$ School of Economics and Trade, Jilin Engineering Normal University, Changchun, 130052 Jilin, China \\ Correspondence should be addressed to Ziyu Liu; lzy19690818@jlenu.edu.cn
}

Received 6 October 2021; Revised 29 October 2021; Accepted 5 November 2021; Published 8 December 2021

Academic Editor: Haibin Lv

Copyright (c) 2021 Xing Chen and Ziyu Liu. This is an open access article distributed under the Creative Commons Attribution License, which permits unrestricted use, distribution, and reproduction in any medium, provided the original work is properly cited.

\begin{abstract}
The "new land-sea corridor" has brought cross-border facilitation and increased trade financing channels. It not only has long been a road-sea transportation corridor but also has been upgraded to a trade corridor. As one of the most inclusive cities, Chongqing, with the help of this channel, can bring more dividends and international resources to the entire western region. Through the logistics base of Singaporean-Chongqing cooperation in multimodal transport, Chongqing can play an important role as a channel operation center and an important logistics hub. Some international shipping resources will be extended to Chongqing, letting the whole western region share the agricultural by-products brought by Southeast Asian countries. Multimodal transport is a common mode of transport in international trade; it combines various modes of transport organically, brings into play the advantages of various modes of transport, and can reduce costs to a large extent. At present, multimodal transport is mostly used for importing and exporting goods; multimodal transport is not widely used in agricultural by-product logistics transportation. Multimodal combination will be used in the transportation of agricultural byproduct logistics; it can avoid the shortcomings of simply using road transportation and make the logistics transportation cost of agricultural by-products lower and management more convenient. Based on the large data, this paper considers factors such as route factors, transfer mode selection, and window meeting time in the transfer process; a mathematical model and advanced colony ant algorithm can be used to solve the transfer optimization problem of a very large fleet of agricultural byproduct logistics. This solution can provide instructions and suggestions for companies that should increase relevant scientific research.
\end{abstract}

\section{Introduction}

In August 2019, China recently issued the Master Plan for a new land-sea corridor in the West. This is an important measure to deepen the two-way opening-up of land and sea and to promote the development of the western region to form a new pattern. The planning period is from 2019 to 2025, and the outlook is to 2035. Located in the hinterland of Western China, the new land-sea corridor links the Silk Road Economic Belt to the north and the 21st century Marine Silk Road to the south. It coordinates with the Yangtze River Eco- nomic Belt and plays an important strategic role in the coordinated development of the region. The plan points out that with the deepening of the strategy of regional coordinated development, the great development of the western region still faces arduous tasks. It is necessary to further strengthen the construction of transportation infrastructure in the western region, expand the existing channel capacity, coordinate the development of the Yangtze River Economic Belt, and improve the quality and efficiency of logistics development. "New land-sea corridor" is an important part of the China-Singapore (Chongqing) strategic interconnection 
demonstration project, the third intergovernmental cooperation project between China and Singapore. In November 2018, Premier Li Keqiang of the State Council of China and Prime Minister Lee Hsien Loong of Singapore held talks, pointing out that taking the signing of the memorandum of understanding on the "new road between land and sea" as an opportunity, land and sea go hand in hand to promote two-way interconnection [1]. Since then, the "South-to-South Passage" in the Sino-Singapore (Chongqing) strategic interconnection demonstration project cooperated by China and Singapore has been officially renamed "New Road for International Land-Sea Trade" (referred to as "New Road for Land-to-Sea Trade") nine months after it was proposed. Agricultural by-products are perishable, difficult to store, and difficult to transport for a long time. As a result, producers are facing greater market risks. Many agricultural products and group products cannot achieve "flow of goods" and "optimal value for money" [2]. The reason is that the logistics of agroindustrial and segmented markets in Southeast Asian countries are backward, with a low level of transparency, poor networks, incomplete information, high disparity rates, and levels low of logistics and equipment. In this case, reducing the logistics cost of agricultural by-products and improving the efficiency of logistics have become an important way to promote agricultural development and increase farmers' income [3].

Because the history of logistics research in our country is not long, the research of logistics theory is relatively weak and lagging behind, and the theoretical system has not been established. In the new wave of "logistics fever," there are fewer studies on agricultural by-product logistics and even fewer studies on logistics combined with a certain region. The domestic research on agricultural by-product logistics mostly focuses on the research of agricultural by-product logistics, model-by-market development model, role of the supply chain in the agricultural sector by market, distribution of logistics by market, macrotraining of limitations of development of agricultural products by market, and countermeasures [4-6]. These studies provide ideas for the development of agricultural by-product logistics in China and provide a theoretical basis for further research of agricultural by-product logistics [7]. However, we can also see that much of the research focuses on macrobarriers and limitations of agroindustrial development and group product sectors. There are also a few studies that apply some of the techniques of modern logistics development to the agroindustrial and product sectors of the group, but there is a lack of indepth research. And in conjunction with specific areas for system analysis and investigation [8], this paper tries to improve the level of research and construction of agricultural by-product logistics, so that most of the agricultural by-products can truly achieve "smooth flow of goods" and "value for money." Multimodal transport refers to the use of two or more modes of transport in the process of logistics transportation and distribution, the realization of convergence and transshipment among various means of transport, and ultimately the completion of the entire transport process together. There are five modes of logistics transportation: highway, railway, waterway, aviation, and pipeline. Automo- bile logistics can be transported by highway, railway, and waterway. In recent years, with the rapid development of railway transportation and waterway transportation, byproduct logistics has gradually begun to use these two modes of transportation [9]. However, in the transport of commodities in my country, only roads and waterways account for $7 \%$ and $8 \%$ of the total commodity transfer by market. Compared with traditional road transportation, railway transportation and waterway transportation have great cost advantages in long-distance transportation [10]. For example, a freight charge always accounts for only $70 \%$ to $80 \%$ of the freight charge. However, train and boat transportation are not beneficial in short distances and low-level transportation. Therefore, if the road, railway, and waterway transportation can be flexibly used and allocated in the logistics transportation of by-products, it will inevitably save costs for enterprises.

This includes the use of comprehensive data collection and analysis, logical and inductive extraction, SWOT process analysis, and energy analysis to study the construction and management of agricultural and product logistics systems on the West Coast. The significance of this study is to study the advantages and disadvantages of various modes of transport, integrate their advantages, and study the special transportation problem of agricultural by-product logistics, apply the technology of researching practices to propose a suitable model, and then find the appropriate algorithm, find the method of transporting multiple vehicles, and finally help the corresponding company save money.

\section{Proposed Method}

2.1. The Elements and Characteristics of the Logistics System of By-Agricultural Products. The logistics system of byagricultural products is composed of various elements of logistics, and there is an overall organic relationship between the elements [11]. The local elements of a logistics system by-product can be divided into general elements, functional elements, and supporting elements. General elements refer to three elements: human, mushroom, and material; service elements refer to transfer, storage, packaging, loading and unloading, distribution, processing, distribution, and logistics services; support elements refer to programs, rules and regulations, and program management.

The characteristics of the logistics system of byagricultural products are as follows: (1) The logistics system of by-agricultural products is a multiobjective system. The general goal of a product logistics system is to determine the efficient transfer of products in the field. Around this general goal, there will be many goals $[12,13]$. For example, the logistics quantity should reach the appropriate scale, the logistics time should be the shortest, the logistics service should be the best, and the logistics cost should be the lowest. (2) The logistics system by the market is a large-scale program. This is especially true for regional geography, as many products are often distributed in different regions [14]. The main problem of long-distance planning is that it is difficult to manage and very reliant on information. (3) The by-product logistics system is a dynamic system. Firstly, 
the logistics system of by-agricultural products is often composed of multiple operation subjects. The elements and operation of the system often change, which makes it difficult to maintain long-term stability. Secondly, by-product logistics is strongly influenced by seasonality, and the requirements for logistics systems vary greatly in different seasons, which also determine that the operation of the logistics system is difficult to be stable $[15,16]$. Dynamics requires that the system must be flexible and changeable. (4) Benefit deviation exists among the functional elements of the by-product logistics system. This mainly refers to the improvement of the efficiency of one of the functional elements in the logistics system which does not necessarily improve the efficiency of the whole system and sometimes even has a negative effect. For example, the transfer of the logistics system is advanced, but the logistics information function is declining. Blindness and poor mobility will cause a large pension of products and cause losses. The separation of interests requires that we look at the logistics from a system perspective, so that all the links of logistics can be integrated with each other to maximize overall efficiency [17]. There are three main components of the industrial structure elements of the logistics system of by-agricultural products: one is the logistics platform, the other is the logistics operation enterprises, and the third is the logistics settlement platform. The logistics platform includes the logistics facility platform, logistics information platform, logistics policy platform, and other parts. The entities of the logistics platform can be divided into two parts: routes and nodes. From the perspective of regional planning, logistics nodes refer to regional logistics hubs, regional logistics centers, etc. Logistics routes refer to highways, railways, airlines, navigation routes, and other logistics channels. The logistics operation enterprise is the main body of micrologistics operation, which operates on the supporting platform and is the leading force to make the whole logistics system move [18]. The logistics distribution platform refers to the whole process of spending and distribution of resources from the fields of production, exchange, storage, transfer, and packaging.

2.2. Analysis of Multimodal Transport of Agricultural and Sideline Products. Many businesses are divided according to the route, which is divided according to the different modes of transportation that are involved in heavy transport, as follows. (1) Land-land transport refers to two modes of transport on land, one by one, and the combined transport of roads and railways $[19,20]$. This type of joint transportation is very common. There are very few transportation tasks that can be completed by rail transportation. Basically, road transportation is required to collect and distribute goods at the ends. This kind of joint transportation can give full play to the advantages of large railway transportation volume, high speed, high security, low cost, etc., and at the same time, it can achieve the purpose of terminal distribution to the household. With the continuous improvement of China's railway line network, the railway operation has been speeding up, and the railway has been extended to China's vast field. This mode of transportation has become more and more spacious and has broad prospects. (2)
Land-to-air intermodal refers to the combination of air transport and road transport and rail transport to complete the transport mission, which is generally used to transport high value-added, time-sensitive cargo that requires air transport. Land and air transport can also be divided into three forms: railway, public, and iron. (3) Sea-air transport refers to the connection of air transport and maritime transport to complete the transport mission. In sea-air transport, maritime transport is usually the mainstay, and air transport is responsible for the final section of the mission, so that the advantages of low maritime transport costs can be fully utilized, and the timeliness of air transport can be applied. However, in the actual implementation process of sea and air transportation, it is inseparable from the intermediate connection process of road transportation [21]. (4) Land and sea transport refers to the connection of maritime transport with road transport and rail transport to complete the transport mission. This type of transportation is generally aimed at bulk cargo and long-distance transportation tasks. The entire transportation process has cost advantages and consumes less energy. China's import and export cargo transportation is also mainly realized through land and sea transportation. This type of intermodal transportation has been developed relatively well, with specialized agents and carriers, which provide convenience for enterprises. (5) Continental bridge transportation is actually a kind of sea-rail combined transport, which refers to the use of railways or highways to connect with the mainland to complete the transportation tasks. This method is very important in current international transportation, which can save a lot of transportation time, improve transportation efficiency, and finally promote the development of international trade.

\subsection{Improved Analysis of Ant Colony Algorithm. Biointelli-} gence has always been the focus of scientists and has become a source of inspiration for scientists to develop new algorithms or designs. The intelligent behavior of colony animals such as bee colonies, flocks, and ant colonies has also attracted the attention of scientists. According to Scientist Gross, by observing and experimenting with the foraging behavior of ant colonies, an explanation is given about pheromones: each ant leaves a pheromone on the passing road during the foraging process; the concentration of pheromone will produce a path for the ant behind [22, 23]. The higher the concentration of pheromone, the greater the probability that subsequent insects will choose this method; however, pheromone concentration will decrease slowly over time and will increase with the number of duck insects passing by. Influenced by Gross's observations, MarcoDorigo et al. linked the intelligent behavior of ant foraging to the classic traveling salesman problem and proposed an ant system concept to solve the traveling salesman problem, which is the basic ant colony algorithm. The colony algorithm primarily utilizes the communication and cooperation characteristics between individual insects by releasing pheromone in the process of insect repellent. The colonial colony algorithm uses insect colonies to simulate behavior. Their behaviors are consistent with the following rules: (1) each time the artificial ant loops, a taboo table is created to record 
the path that has passed, which has appeared in the taboo table. The path in the loop will not be selected again in this cycle; (2) when the artificial ant selects the path that has not passed, it will make a selection according to the concentration of the pheromone on each path. The higher the concentration of the pheromone, the greater the probability that the path is selected; (3) each time the artificial ant completes the cycle, the pheromone of the corresponding concentration is released according to the length of the entire path, and the pheromone concentration on the path is updated. The transition probability is specifically expressed as follows:

$$
\begin{aligned}
P_{i j}^{k} & = \begin{cases}\tau_{i j}^{\alpha}(t) \eta_{i j}^{\beta}(t), & j \in \text { allowed } k, \\
0, & \text { otherwise, }\end{cases} \\
\text { Jaccard } & =\frac{\mid \text { SEG } \cap \mathrm{GT} \mid}{\mid \text { SEG } \cup \mathrm{GT} \mid}, \\
x_{H} & =\frac{p_{2}-p_{1}+1}{2} .
\end{aligned}
$$

In formula (3), allowed $k$ or transfer city node that ant $A$ can choose when it is at city node $i$; artificial ant colony has memory function, tabuk is a taboo table that records the city node that ant $A$ has traveled, it will follow. The artificial ant's search behavior is dynamically adjusted; $\alpha$ and $\beta$ are the two computational factors of the ant colony algorithm, $\alpha$ is the information heuristic factor and $\beta$ is the expected heuristic factor; $n_{i j}$ is the expected degree of the artificial ant moving from the urban node $i$ to the urban node $j$ [24]. In the traveling salesman problem, the shorter the distance between the city node $i$ and the city node $j$ is defined, the higher the degree of expectation of sending a transfer, and the greater the transition probability. As long as the pheromone develops slowly over time, the parasites will update the pheromone in each direction after the end of all cycles. By using the parameter $\rho$ to represent the pheromone volatilization coefficient, $1-\rho$ is the information residual factor, which prevents the infinite accumulation of pheromones. The way pheromone is updated can be expressed in the following two ways:

$$
\begin{aligned}
\tau_{i j}^{\text {new }} & =(1-\rho) \tau_{i j}^{\text {old }}+\Delta \tau_{i j}, \\
\Delta \tau_{i j} & =\sum_{k=1}^{m} \Delta \tau_{i j}^{k} .
\end{aligned}
$$

In equations (4) and (5), the amount of pheromone left by all the artificial ants passing through the path $(i, j)$ in this cycle is represented, indicating that the $k$ th artificial ant passing the path in this cycle $(i, j)$ is the amount of pheromone left behind. The parameter setting in the ant colony algorithm has a great influence on the performance of the algorithm. The number of artificial ants Dorigo studied the influence of the placement position of artificial ants on the experimental results. The results show that the solution effect of placing artificial ants separately into different cities is better than solving all the artificial ants in the distribution.
The effect is better. At the same time, the number of artificial ants also has a great influence on the solution effect. When the number of artificial ants is small, the pheromone gradually evaporates over time, and the pheromone on many paths volatilizes prematurely, which makes the search quality of the algorithm decrease. When the problem scale is large, the effect is more obvious. Adding a certain amount of artificial ants can improve the global search ability of the ant colony algorithm, improve the stability of the algorithm, and ultimately improve the quality of the solution but continue to increase the number of artificial ants, so that when the number is too large, the number of pheromones on each path will be caused. The difference is not so obvious, which will slow down the convergence of the algorithm, which is not conducive to improving the quality of the solution.

After using the genetic algorithm to improve the ant colony algorithm, the pheromone initial setting of the ant colony algorithm needs to be adjusted:

$$
\begin{aligned}
\tau_{s} & =\tau_{c}+\tau_{c i}, \\
U_{2} & =\left\{\begin{array}{l}
s-p_{1}-k x_{2}, \\
x-p_{2}-k\left(1-x_{2}\right) .
\end{array}\right.
\end{aligned}
$$

$R$ coefficient calculation formula:

$$
R=100 \% \times\left(1-\frac{|R|-|k|}{|k|}\right)
$$

In formula (7), $\tau_{c}$ refers to a pheromone constant given according to a specific problem, and $\tau_{c i}$ is a pheromone transformed according to a solution result of the genetic algorithm. The pheromone update rule of the ant colony algorithm is adjusted as follows:

(1) The general update rule of pheromone:

$$
\begin{aligned}
\tau(i, j) & =(1-\omega) \tau(i, j)+\omega \Delta \tau(i, j), \\
\Delta \tau(i, j) & =\left\{\begin{array}{l}
\frac{1}{L_{g h}}(i, j \text { in the optimal solution }), \\
0, \text { else. }
\end{array}\right.
\end{aligned}
$$

Equations (8) and (9) indicate that after all artificial ants have completed a traversal, only the path of the ant with the optimal solution is selected for the pheromone update, where $\omega$ represents the global pheromone volatilization coefficient and $l g b$ represents the traversal, the path length of the optimal solution.

(2) Pheromone local update rules: 


$$
\begin{aligned}
\tau_{y}(t+1) & =(1-\rho) \tau_{y}(t)+\rho \tau_{0}, \\
R & =\sum_{x=1}^{\theta} V x=\sum_{x=1}^{\vartheta}\left(\frac{W x}{\sum_{1}^{n} W_{\mathfrak{J}}} S x\right) .
\end{aligned}
$$

$R$ and GT coefficient calculation formula:

$$
\rho=1-\frac{|R \cap \mathrm{GT}|}{|R \cup \mathrm{GT}|} .
$$

In order to obtain a reliable original boundary within the new terrestrial channel, the network uses a hybrid simulation function to reduce the gap between the new terrestrial channel and the marked image:

$$
\begin{aligned}
S^{(k)} & =\partial_{1} f_{\mathrm{bce}}^{(k)}+\partial_{2} f_{\mathrm{iou}}^{(k)}+\partial_{3} f_{\mathrm{ssim}}^{(k)}, \\
f & =\frac{n \sum_{i=1}^{n} \sum_{j=1}^{n} w_{i j}\left(x_{i}-\bar{x}\right)(x j-\bar{x})}{\sum_{i=1}^{n} \sum_{j=1}^{n} w_{i j}(x i-\bar{x})^{2}} \\
& =\frac{n \sum_{i=1}^{n} \sum_{i \neq j}^{n} w_{i j}\left(x_{i}-\bar{x}\right)(x j-\bar{x})}{S^{2} \sum_{i=1}^{n} \sum_{j=1}^{n} w_{i j}} .
\end{aligned}
$$

$I$ is the superparameter of each loss function. BCE loss function is the most widely used loss function in binary classification and channel:

$$
\begin{aligned}
S & =\beta X+(\operatorname{In}-\alpha W)^{-1} \varepsilon, \\
W_{\kappa} & =\frac{2 k}{k+1}+\left[\frac{1}{2}+\frac{1}{2 k}\right]\left[\frac{c_{2}-c_{1}}{3}\right]^{2}+\frac{2\left(c_{2}-c_{1}\right)}{3},
\end{aligned}
$$

where $s$ and $W$ represent the height and width of the input image, respectively. Cross-border facilitation can be used for image quality assessment, through which the structural information of the new land-sea channel can be obtained. Therefore, if it is integrated into the loss function of the network, the structural information of the annotated image can be obtained. $S$ and $W$ represent the pixel values of the corresponding areas of the channel image and the expert annotation image, respectively, and the cross-border convenience of $X$ and $Y$ is defined as $C$ :

$$
C_{\text {ssim }}=1-\frac{\left(2 \mu_{x} \mu_{y}+C_{1}\right)\left(2 \sigma_{x y}+C_{2}\right)}{\left(\mu_{x}^{2}+\mu_{y}^{2}+C_{1}\right)\left(\sigma_{x}^{2}+\sigma_{y}^{2}+C_{2}\right)} .
$$

The loss function of cross-border convenience considers the local neighborhood of each pixel. A higher weight can be assigned to the boundary. Since the loss along the boundary is the largest at the beginning of training, the use of crossborder facilitation helps to optimize the extraction of boundary features. When combining the three losses, the $C$ loss function is used to maintain a smooth gradient for all pixels, and the $C$ loss function is used to pay more attention to the similarity. The cross-border convenience loss function is used to optimize the channel details through the large loss near the boundary to improve the image channel accuracy:

$$
G_{1}=\left\{\begin{array}{l}
s-p_{1}-x_{1}, \\
x-p_{2}-\left(1-x_{1}\right),
\end{array}\right.
$$

$$
\ln A_{i t}=a_{0}+a_{1} d u * d t * G+\sum_{i=1}^{N} b_{j} X u+\varepsilon_{u} .
$$

Equation (18) indicates that the artificial ant updates the pheromone on the corresponding path after transferring between the nodes, indicating the local pheromone volatilization coefficient. By using the global pheromone and the local pheromone update rules at the same time, the ant colony algorithm can be prevented from falling into the local optimal solution, and a better solution can be found.

\section{Experiments}

In the traditional single-road transportation model, since the transportation of agricultural products in Southeast Asian countries is directly from the producer to the distributor, the rate on each line can be obtained only by the transportation distance and the freight rate of the corresponding line. In the use of the multimodal transport model of agricultural and sideline products, it is much more complicated. For the rate on each line, not only the information of the distance should be obtained but also various expenses, such as the short-distance transportation cost of the road at both ends, railway transportation, and water transport transported by shift. If the minimum transport requirement is not met, then there will be storage time of agricultural products at the train station and dock, which will bring costs, and the corresponding costs on each route will not be the same. Again, this increases the difficulty of collecting model data. Although it is difficult to obtain exact model data, manufacturers can understand supply and demand conditions, rationally set the levels of agricultural products, reduce and maintain parking costs at train stations and terminals, or sign a complete service contract including the carrier. The speed of each line is fixed, which solves problems using the model $[25,26]$.

The transportation of public iron-water involves transportation modes and nodes. The comprehensive transportation cost is composed of the transportation mode cost and the node transit cost. In practice, the time value should be additionally considered. The cost of highway nodes is $16.58 \sim 22$ yuan/ton, and the fee is $23.3 \sim 33.6$ yuan/ton; the cost of the port node is 32.09 34.58 yuan/ton, and the charge is 24 26 yuan/ton. Considering the cost separately, the cost of road and road transport is highest in each category. The whole society should plan to reduce the share of rail transport and increase the share of rail transport to reduce the transport costs. In the iron-water combined transport mode, compare the direct railway stationed in the port and the short distance to the port cost change. According to whether the Chongqing port has the conditions of iron-water combined transport and port throughput capacity, select the central point of Chongqing (main city 


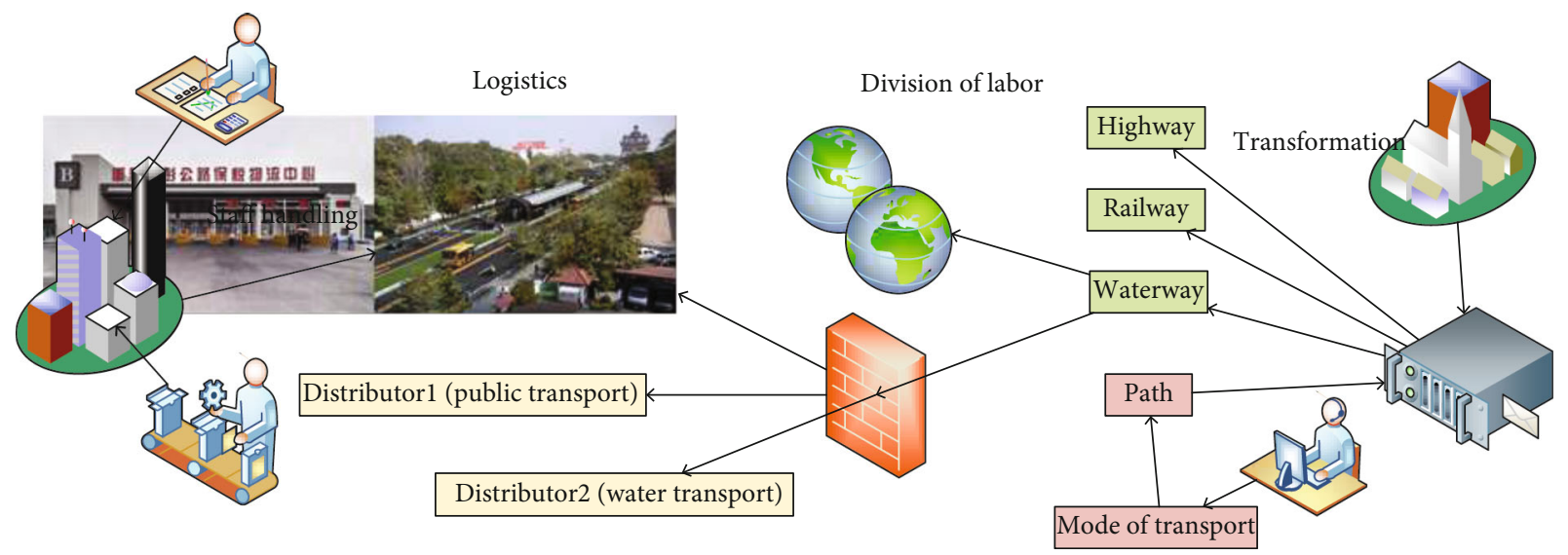

FIGURE 1: VSC vehicle storage center.

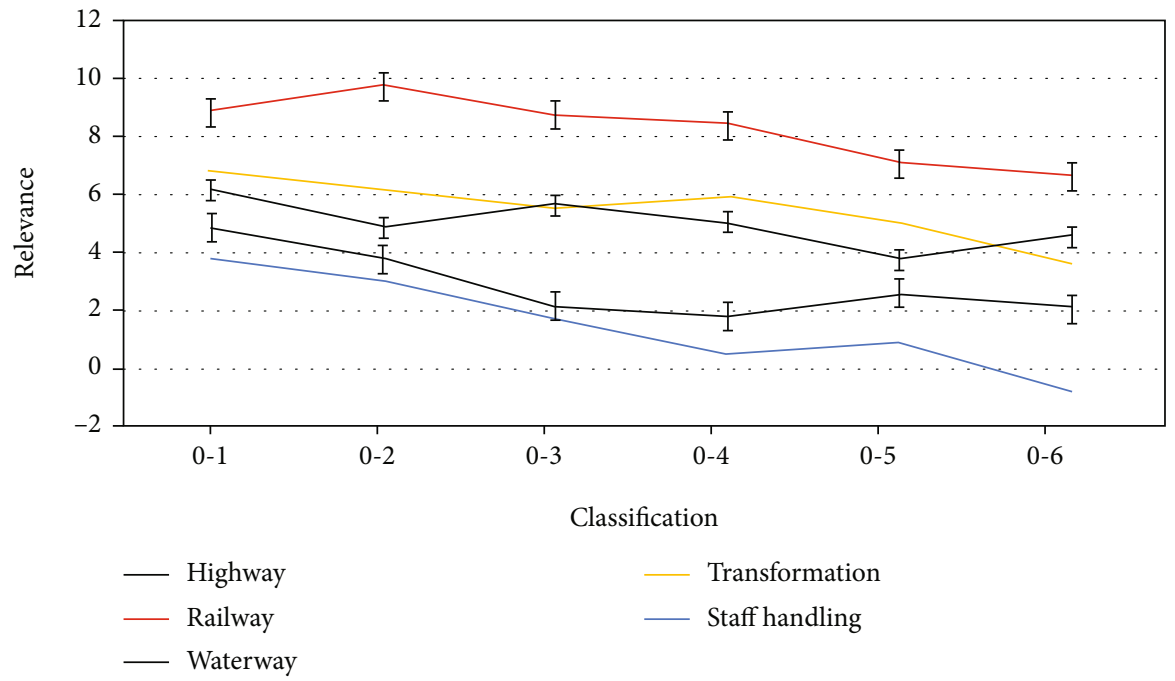

FIgURE 2: Distances of various modes of transportation.

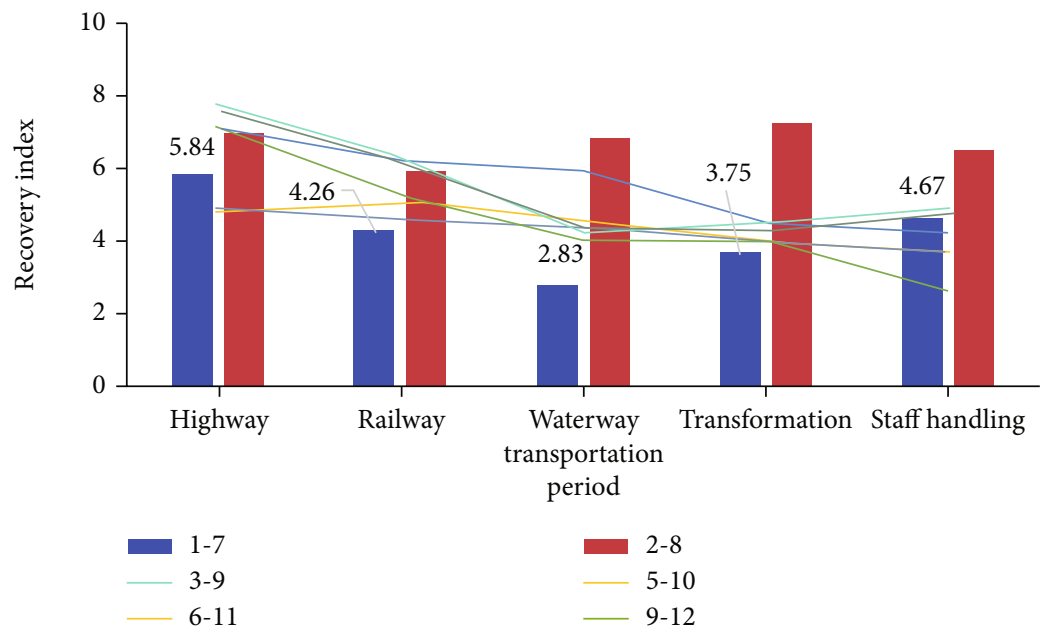

FIgURE 3: Transportation network and hardware equipment conditions.

Cuntan port, orchard port, Donggang) and Northeast point (Wanzhou Jiangnan, Wanzhou Hongxigou) as a pilot port for hot metal water transport analysis of the seamless con- nection mode of hot metal water transport and the short cost of the road to the port mode. The goods are directly loaded into the port from the railway without intermediate 
TABLE 1: Technical characteristics of various transportation modes.

\begin{tabular}{lccccc}
\hline Item & Distance limit & Technology & Economic & Energy consumption & Short distance \\
\hline Transformation & 12.09 & 3.97 & 3.21 & 11.45 & 11.82 \\
Staff handling & 12.65 & 5.12 & 2.54 & 13.62 & 7 \\
Division & 11.65 & 5.51 & 2.72 & 12.2 & 6.5 \\
Highway & 10.44 & 5.53 & 2.07 & 11.36 & 5.42 \\
Railway & 9.44 & 4.16 & 2.58 & 11.2 & 5.69 \\
Waterway & 7.64 & 3.86 & 2.53 & & 5.1 \\
\hline
\end{tabular}

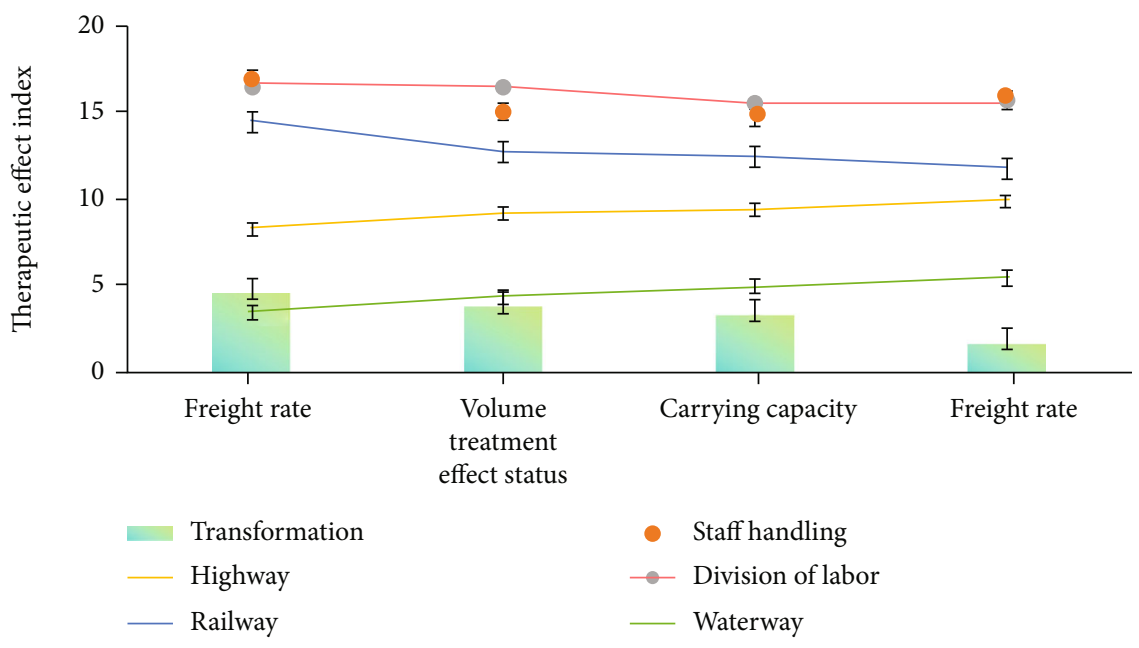

FIgURE 4: Delivery speed of different transportation tasks.

loading and unloading. The mode 2 road short barge needs to increase the number of unloading trains at the railway station. The cost is different firstly, the short barge transportation increases the loading and unloading cost, and the second is the cost of railway transportation and road transportation during transportation. The cost difference between the two modes = loading and unloading cost + road transportation cost - railway transportation cost; after simplification, cost difference $=$ cargo quantity $*$ (loading cost + freight rate difference $*$ mileage). If the cargo capacity of the five ports (Cuntan, Orchard, Donggang, Wanzhou Jiangnan Pass, and Wanzhou Hongxigou) is $20 \%$, the combined transport mileage comparison model will reduce the cost by 265 million yuan, $89 \%$ of the cost of road shorting.

\section{Discussion}

This paper selects 9 VDCs (including Anting total warehouse), IS large VSC vehicle storage center. The situation of these VDC and VSC is shown in Figure 1. Of the total of 9 VDCs and 15 VSCs, 6 VDCs and $S$ VSCs belong to individual brand warehouses, and their distribution and transportation need to be arranged separately according to the needs of these brands. When the agricultural and sideline product logistics companies studied in this paper do not consider these special libraries, they only consider the remaining 3 VDCs and 10 VSCs, which can be used by all brands.
The logistics route of agricultural and sideline products of new channel is shown in Figure 1. Although only one line is used for connection between urban areas, this line represents the possibility of unification of multiple transport routes, but in actual transmission, the route between each of the two cities can only select the type of transmission.

As shown in Figure 2, different routes of different transport methods will lead to different lengths, and the technological speed of different transport methods will also vary. Therefore, it is necessary to count the distances of various modes of transportation on each path. According to the analysis of existing road transportation, railway transportation, and water transportation network, this paper first judges whether there are three kinds of transportation modes between each two city nodes and then according to the road transportation, railway transportation, and waterway published on the Internet.

As shown in Figure 3, each mode of transportation has its own characteristics, namely, its respective advantages and defects. The purpose of multimodal transport is to combine these modes of transport, to exert their strengths, to circumvent their respective defects, and finally to complete the transportation task. The concept of mass transport is very good, but its implementation process must first be related to the current transmission network and the application conditions of most transport systems.

As shown in Table 1, all kinds of transportation methods have only considered their own service objects in the previous development, and their respective hardware equipment 

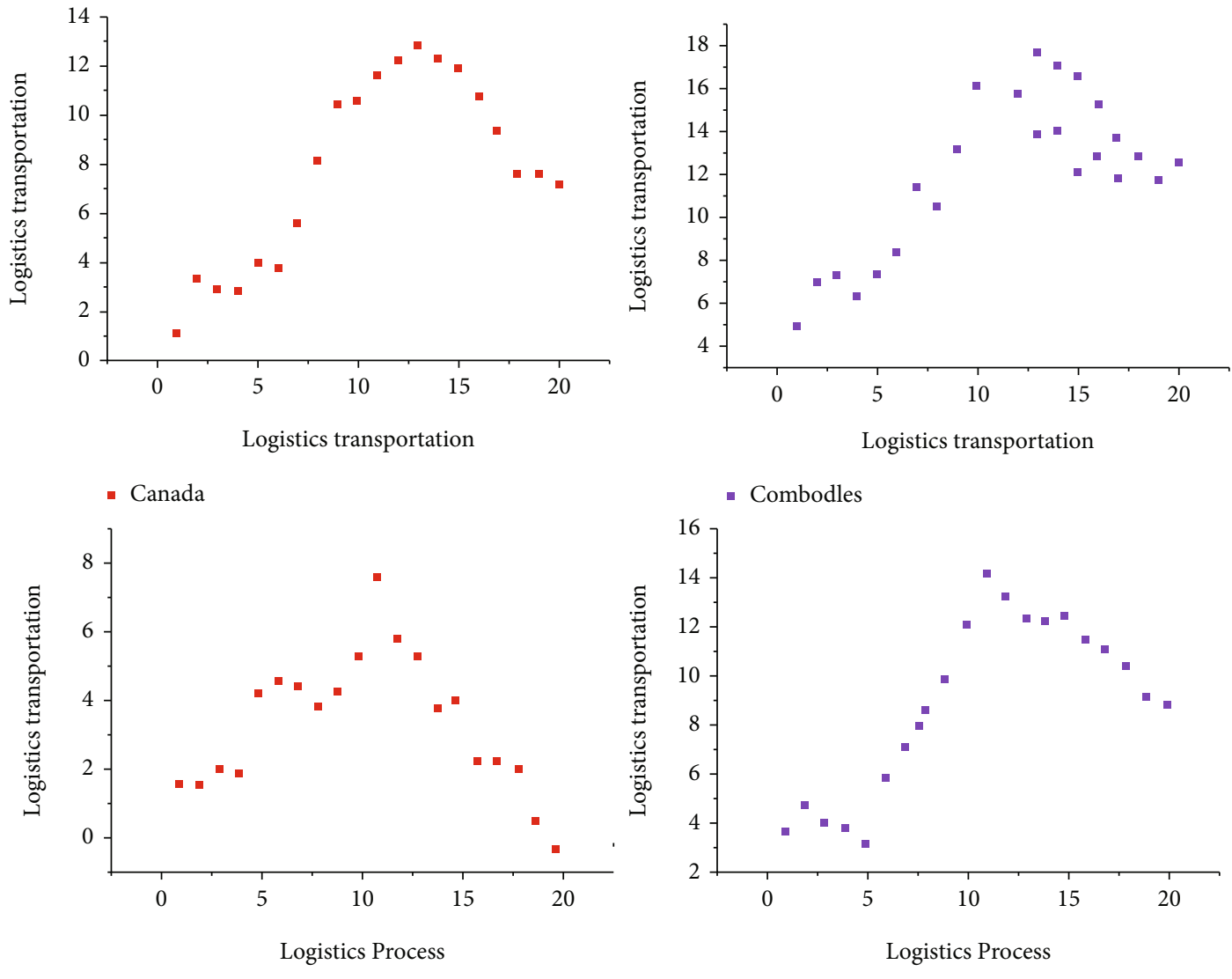

- Cameroon

- China

FIgURE 5: Cost of fixed facilities for railway transportation.

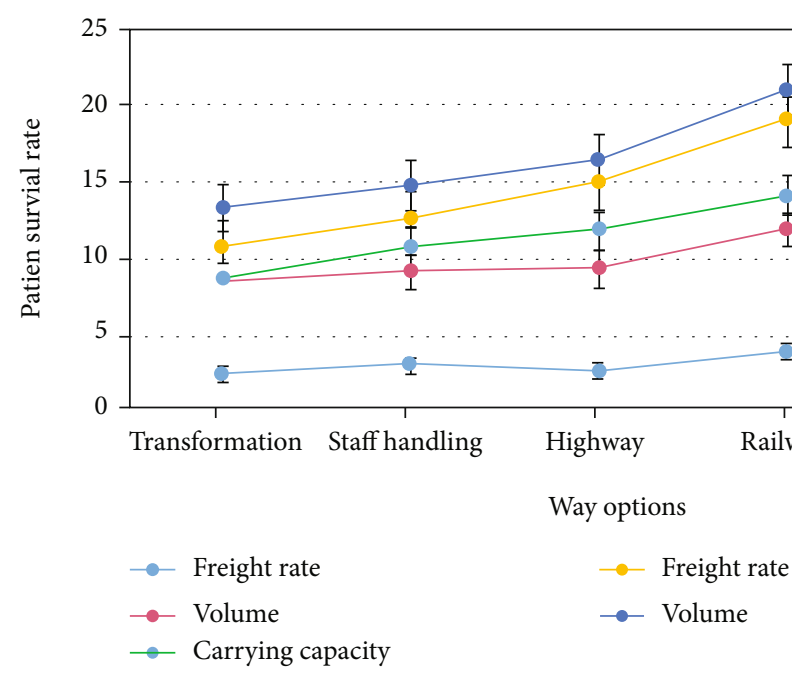

Figure 6: Perspective of operating costs.

constructions are also different, and some aspects cannot be used interchangeably. The "transportation service" effect that multimodal transport wants to achieve is not only the part of the transportation supplier and the demand side that directly contacts but also the hardware level that the intermediate transportation company can provide and the tech- nical characteristics of various transportation modes. Among the many transport methods, pipeline transport is incompatible with other transportation systems due to its technological characteristics. Therefore, this paper only studies four modes of transportation: railway, waterway, highway, and aviation. 


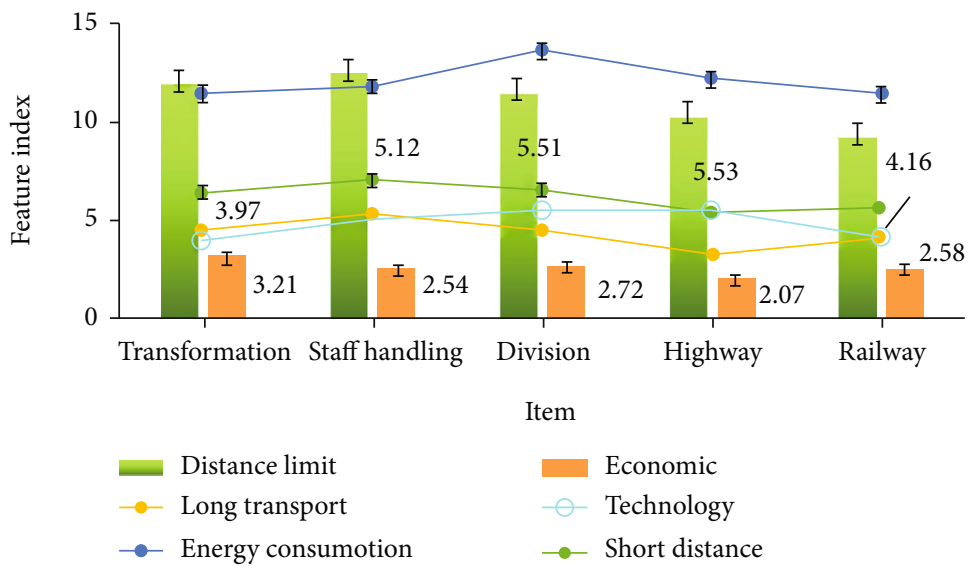

Figure 7: Kinds of transportation modes.

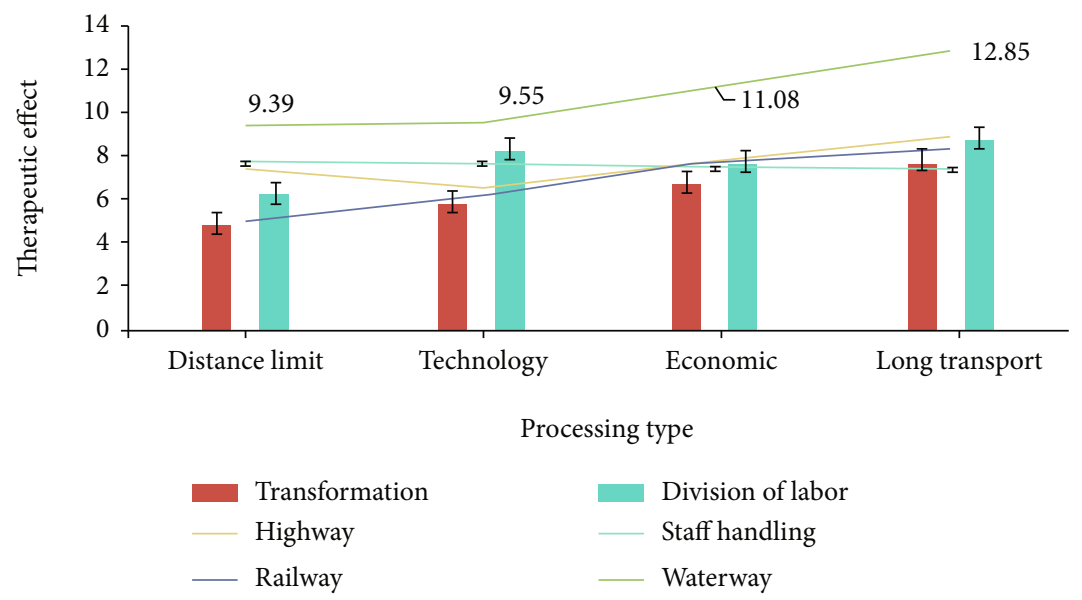

Figure 8: Aggravation of the energy crisis.

TABle 2: Statistical table of transportation distances of transportation modes among urban nodes (unit: kilometer).

\begin{tabular}{lcccccc}
\hline \multirow{2}{*}{ Party style } & \multicolumn{7}{c}{ Transportation distance between nodes } \\
& $0-1$ & $0-2$ & $0-3$ & $0-4$ & $0-5$ & $0-6$ \\
\hline Highway & 906 & 1114 & 890 & 1341 & 2060 & 2060 \\
Railway & 1252 & 1196 & 608 & 1470 & 21185 & - \\
Waterway & 1298 & 727 & 1044 & - & - & 1566 \\
& $1-7$ & $2-8$ & $3-9$ & $5-10$ & $6-11$ & $9-12$ \\
Highway & 399 & 137 & 867 & 1903 & 1436 & 375 \\
Railway & - & - & 876 & 1757 & 1616 & 374 \\
Waterway & - & - & 1275 & - & - & - \\
\hline
\end{tabular}

As shown in Figure 4, the transportation speed of transportation mode includes both technical speed and delivery speed. The delivery speed of various modes will be affected by the transit time and transit time during transportation. The delivery speed of different transportation tasks will be different. For the convenience of research, the speed we are talking about refers to the technology of various transportation modes. Among these four modes of transportation, the speed of air transportation is much higher than the other three modes, and the water transportation speed is the lowest.
As shown in Figure 5, transportation costs are affected by many factors, including fixed costs and operating costs. Fixed costs include fixed facility costs and mobile facility costs for transportation, maintenance and depreciation, etc. Operating costs include fuel costs and labor costs for each transportation process. Operating costs are affected by the distance traveled. Among the four modes of transportation, the cost of fixed facilities for railway transportation is the highest cost of railroads, and the cost of fixed facilities for road transportation is second and then the cost of fixed facilities for aviation.

As shown in Figure 6, this part has the lowest cost of shipping; from the point of view of the value of mobile devices, planes are the highest, followed by ships, then trains, and finally cars and trucks; from the perspective of operating costs, aviation is the highest, the road is second, the railway is the second, and the water transport is the lowest.

As shown in Figure 7, all modes of transport have their own distance restrictions, which are determined by the technical and economic characteristics of the transport equipment and are also affected by different transport tasks. These kinds of transportation modes are in China's current freight market. Train trade and shipping are mainly responsible for medium and long haul. The air transport was carried out by speed and a huge load of charge. Road immigration is mainly 


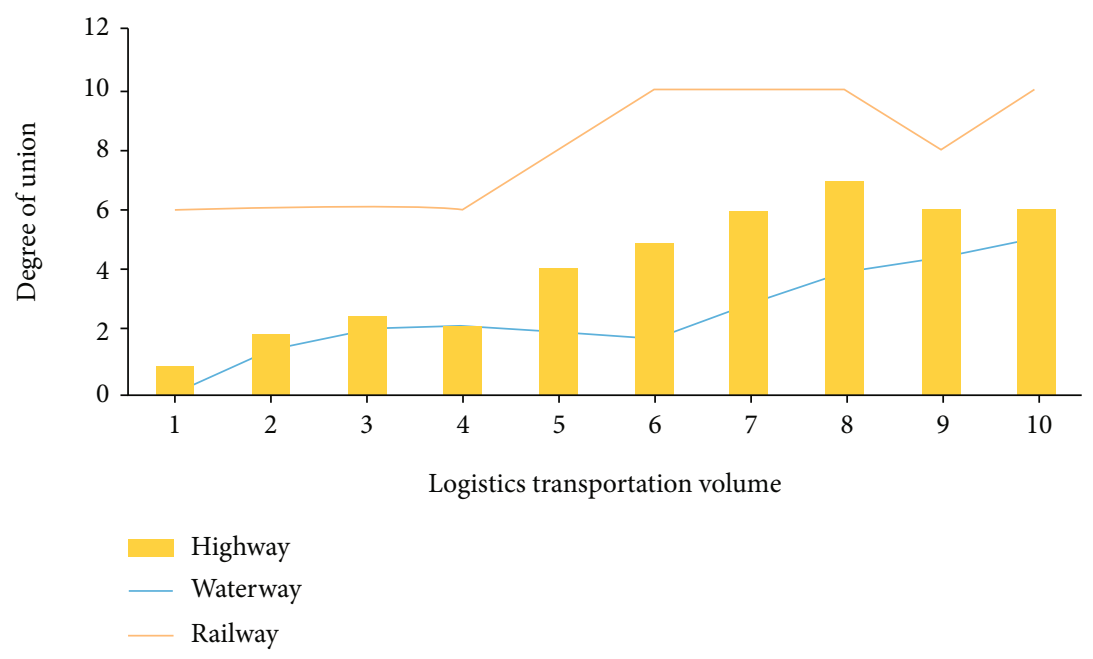

FIGURE 9: Unit conversion fee between various modes of transportation.

TABLE 3: Optimal transportation methods between nodes.

\begin{tabular}{lcccccc}
\hline Path & $0-1$ & $0-2$ & $0-3$ & $0-4$ & $0-5$ & $0-6$ \\
\hline Mode of transport & Waterway & Waterway & Waterway & Railway & Highway & Highway \\
Path & $1-7$ & $2-8$ & $3-9$ & $5-10$ & $6-11$ & $9-12$ \\
Mode of transport & Highway & Highway & Highway & Waterway & Railway & Highway \\
\hline
\end{tabular}

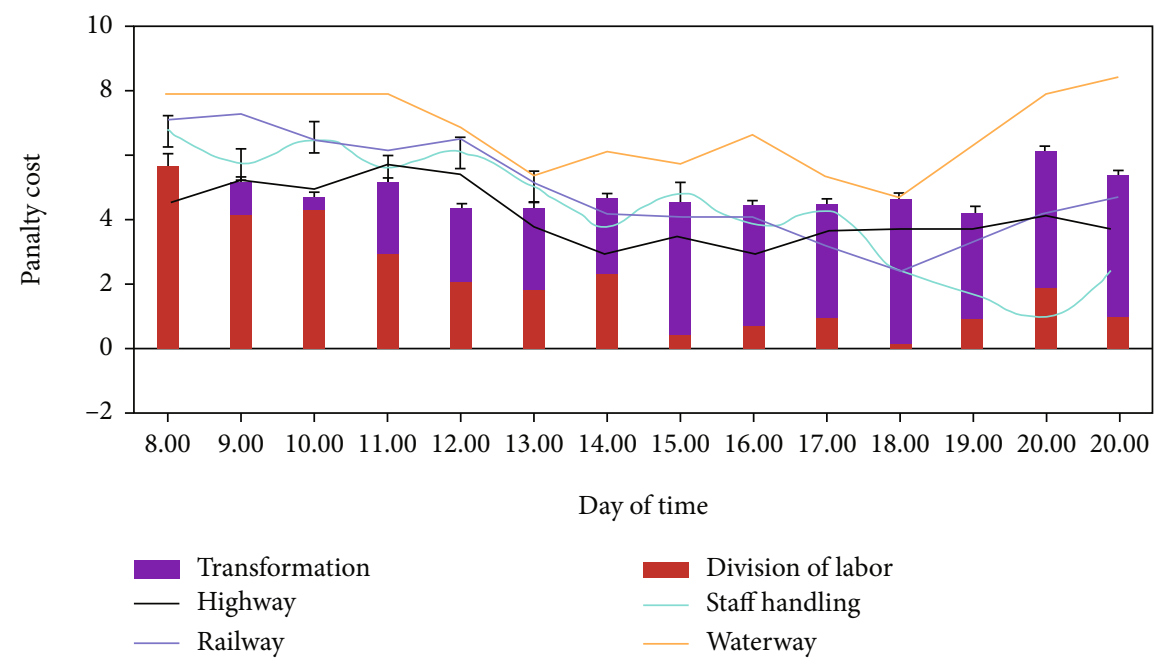

FIGURE 10: Time window of each node.

responsible for short-distance transportation, but in China. In the logistics and transportation industry, road transport will also be a long-distance transport.

As shown in Figure 8, with the aggravation of the energy crisis and the increasing environmental pollution, the energy consumption of the transportation industry has become the focus of attention of the entire country. In developed countries, the energy consumption of the transportation industry accounts for $30 \%$ of the total energy consumption in the country. China currently accounts for about $8 \%$, indicating that there is still much room for development in China's transportation industry, but we must also pay attention to improving energy utilization. Among these four modes of transportation, road transportation has the highest energy consumption, air transportation is the second, and water transportation is the least, and road transportation energy consumption accounts for about $80 \%$ of the entire transportation industry. The number of miles traveled is queried for the distances on each path, as shown in Table 2. For the two modes of transportation between two urban nodes, respectively, "_" indicates that there is no such transportation mode between the two city nodes.

There are differences in the single charge of different transfer methods. When selecting transfer locations in 
TABLE 4: Test data under traditional single-road transportation mode.

\begin{tabular}{|c|c|c|c|c|c|c|}
\hline \multirow[b]{2}{*}{ Distributor } & \multicolumn{3}{|c|}{ Producer 1} & \multicolumn{3}{|c|}{ Producer 2} \\
\hline & Freight rate (yuan) & Volume $(\mathrm{t})$ & $\begin{array}{l}\text { Carrying } \\
\text { capacity }(\mathrm{t})\end{array}$ & Freight rate (yuan) & Volume $(\mathrm{t})$ & $\begin{array}{l}\text { Carrying } \\
\text { capacity }(\mathrm{t})\end{array}$ \\
\hline Distributor 1 (water transport) & 210 & $X_{111}$ & 600 & 420 & $X_{211}$ & 700 \\
\hline Distributor 1 (iron transport) & 230 & $X_{112}$ & 300 & 440 & $X_{212}$ & 200 \\
\hline Distributor 1 (public transport) & 250 & $X_{113}$ & 500 & 460 & $X_{213}$ & 300 \\
\hline Distributor 2 (water transport) & 310 & $X_{121}$ & 400 & 370 & $X_{221}$ & 300 \\
\hline Distributor 2 (iron transport) & 330 & $X_{122}$ & 300 & 390 & $X_{222}$ & 400 \\
\hline Distributor 2 (public transport) & 350 & $X_{123}$ & 500 & 410 & $X_{223}$ & 500 \\
\hline Demand $(t)$ & \multicolumn{3}{|c|}{1000} & \multicolumn{3}{|c|}{800} \\
\hline
\end{tabular}

TABLE 5: Test results of multimodal transport.

\begin{tabular}{lcccccc}
\hline \multirow{2}{*}{ Distributor } & \multicolumn{2}{c}{ Producer 1 } & \multicolumn{3}{c}{ Producer 2 } \\
& Freight rate (yuan) & Volume $(\mathrm{t})$ & Cost $(\mathrm{t})$ & Freight rate (yuan) & Volume $(\mathrm{t})$ & Cost $(\mathrm{t})$ \\
\hline Distributor 1 (water transport) & 210 & $X_{111}=600$ & 126000 & 420 & $X_{211}=0$ & 0 \\
Distributor 1 (iron transport) & 230 & $X_{112}=300$ & 69000 & 440 & $X_{212}=0$ & 0 \\
Distributor 1 (public transport) & 250 & $X_{113}=0$ & 0 & 460 & $X_{213}=0$ & 0 \\
Distributor 2 (water transport) & 310 & $X_{121}=100$ & 31000 & 370 & $X_{221}=300$ & 111,000 \\
Distributor 2 (iron transport) & 330 & $X_{122}=0$ & 0 & 390 & $X_{222}=400$ & 156,000 \\
Distributor 2 (public transport) & 350 & $X_{123}=0$ & 0 & 410 & $X_{223}=100$ \\
Total cost (yuan) & & & 534,000 & & 41,000 \\
\hline
\end{tabular}

different areas, single charges also vary. For ease of study, this object ignores the difference in the single charge of the same transfer state in different areas. Referring to the research literature of the previous scholars, the unit cost of each transportation mode unit price and each transportation mode is shown in Figure 9.

According to the comparative analysis of the above optimization results, in the future transportation process, different transportation modes can be selected for different transportation routes. This is a saving of 443,000 yuan over the 4.934 million yuan required for pure road transport. It can be seen that the optimization results are obvious. For example, for the whole vehicle transportation in coastal areas, it is inclined to consider shipping; for the whole vehicle transportation along the Yangtze River, it tends to consider river transportation; for other cities, it tends to use road transportation. In some special cases, such as expedited orders, it can be adjusted to road transport. The time window settings for each node are shown in Table 3 . Set the penalty cost to 1000 yuan per hour per car.

As shown in Figure 10, suppose there are two manufacturers and two distributors, and there are three modes of transportation between each manufacturer and distributor. Each mode of transportation has its corresponding maximum carrying capacity $L$ and corresponding rate $C$. In this way, the relationship between the power, transmission capacity, and speed of each line of two processors and two servers is obtained. The best solution of the model is obtained from the project data. It can be seen from the table the price and volume of each mode of transport between producers and distributors, the maximum carrying capacity of each mode of transport, and the supply capacity of each producer, as well as the demand of distributors.

Table 4 assumed that data, which is an oversupply problem, then continue to use the model to find II to this problem solution, obtained in Table 5 results.

According to the results of Table 5, the optimal solution of the model is 534,000 yuan for two manufacturers and two distributors when multimodal transport is introduced. From the results of these two cases, if the train or cruise rate is less than the train rate, then the model described in this study can increase the total transportation cost, less than the cost of taking a custom train, in order to achieve the promising results of this study.

This study in innovation optimized the multidisciplinary transport network of agricultural products by line design, developed the model, and confirmed the feasibility of the model, in order to achieve the expected effect [27]. However, there are still other problems in the multimodal transport of agricultural products, such as the storage of agricultural products in wharf or warehouse and the shelf life of agricultural products, which will be perfected with the development and research of the subject [28-30].

\section{Conclusions}

Agricultural and sideline product logistics is an important part of logistics. Saving costs in the logistics of agricultural and sideline products can reduce the cost of the entire automotive supply chain. China's current agricultural and 
sideline product logistics market is fiercely competitive, but the mode of transportation is simplistic, and most of them use road transportation. The high cost has become a major obstacle to the development of the automotive industry. Multimodal transport is now widely used all over the world. It can combine the advantages of various modes of transportation and has unique advantages in logistics and transportation. At present, there are still few enterprises that use multimodal transport in China for logistics and transportation. In the application process, many problems are also highlighted, and there are still much development prospects and room for improvement. The application of multimodal transport in the field of agricultural and sideline product logistics can help autologistics companies save costs and promote the development of the entire automotive industry. This paper firstly combs the vehicle routing problem and the agricultural and sideline product logistics-related theory, studies the basic model and common solving algorithm of the vehicle routing problem, and chooses to use the ant colony algorithm to solve the vehicle routing problem. Then, this paper takes the logistics link of agricultural and sideline products as the research object, analyzes the business model of domestic agricultural and sideline products logistics and the development status of multimodal transport of agricultural and sideline products logistics, and establishes the vehicle path optimization with time window for its multimodal transport path problem. For the mathematical model, finally, combined with the VDC and VSC position and demand data obtained from the survey, the shortcomings of the ant colony algorithm are improved, and the improved algorithm is used to solve the model, and finally, the optimized path of multimodal transport is obtained.

\section{Data Availability}

No data were used to support this study.

\section{Conflicts of Interest}

The authors state that this article has no conflict of interest.

\section{Acknowledgments}

This work was supported by the Doctoral Research Initiation Funding Project of Jilin Engineering Normal University, Project number: BSSK201901; Science and Technology Department of Jilin Province soft science project funding, Project number: 20200101073FG; Rural Development Institute of Jilin Engineering Normal University; and Program for Innovative Research Team of Jilin Engineering Normal University.

\section{References}

[1] D. Ambrosino and A. Sciomachen, "A capacitated hub location problem in freight logistics multimodal networks," Optimization Letters, vol. 10, no. 5, pp. 875-901, 2016.

[2] K. Wang, "Logistics management model of fresh agricultural products in the new international land-sea trade corridor based on information network," Revista de la Facultad de
Agronomia de la Universidad del Zulia, vol. 36, no. 4, pp. 1078-1085, 2019.

[3] A. Kengpol and S. Tuammee, "The development of a decision support framework for a quantitative risk assessment in multimodal green logistics: an empirical study," International Journal of Production Research, vol. 54, no. 4, pp. 1020-1038, 2016.

[4] S. H. Woo, S. N. Kim, D. W. Kwak, S. Pettit, and A. Beresford, "Multimodal route choice in maritime transportation: the case of Korean auto-parts exporters," Maritime Policy \& Management, vol. 45, no. 1, pp. 19-33, 2018.

[5] Y. J. Seo, F. Chen, and S. Y. Roh, "Multimodal transportation: the case of laptop from Chongqing in China to Rotterdam in Europe," The Asian Journal of Shipping and Logistics, vol. 33, no. 3, pp. 155-165, 2017.

[6] S. Okyere, J. Yang, and M. Aminatou, "Influence of multimodal transport system dynamics on logistics responsiveness: an ordinal logistic regression approach," International Journal of Civil Engineering (IJCE), vol. 6, no. 6, pp. 9-24, 2017.

[7] D. Zhang, R. He, S. Li, and Z. Wang, "A multimodal logistics service network design with time windows and environmental concerns," PLoS One, vol. 12, no. 9, article e0185001, 2017.

[8] B. Karimi, M. Bashiri, and E. Nikzad, "Multi-commodity multimodal splitc logistics hub location problem with stochastic demands," International Journal of Engineering, vol. 31, no. 11, pp. 1935-1942, 2018.

[9] M. A. Ertem, M. İşbilir, and A. Ş. Arslan, "Review of intermodal freight transportation in humanitarian logistics," European Transport Research Review, vol. 9, no. 1, p. 10, 2017.

[10] F. Zhang, D. M. Johnson, and J. Wang, "Integrating multimodal transport into forest-delivered biofuel supply chain design," Renewable Energy, vol. 93, no. 1, pp. 58-67, 2016.

[11] Z. He, P. Chen, H. Liu, and Z. Guo, "Performance measurement system and strategies for developing low-carbon logistics: a case study in China," Journal of Cleaner Production, vol. 156, no. 1, pp. 395-405, 2017.

[12] Y. Wang, L. A. Kung, and T. A. Byrd, "Big data analytics: understanding its capabilities and potential benefits for healthcare organizations," Technological Forecasting and Social Change, vol. 126, no. 1, pp. 3-13, 2018.

[13] Q. Zhang, L. T. Yang, Z. Chen, and P. Li, "A survey on deep learning for big data," Information Fusion, vol. 42, no. 4, pp. 146-157, 2018.

[14] M. Abdel-Basset, M. Mohamed, F. Smarandache, and V. Chang, "Neutrosophic association rule mining algorithm for big data analysis," Symmetry, vol. 10, no. 4, pp. 106-109, 2018.

[15] W. Xu, H. Zhou, N. Cheng et al., "Internet of vehicles in big data era," IEEE/CAA Journal of Automatica Sinica, vol. 5, no. 1, pp. 19-35, 2018.

[16] X. Wang, Y. Zhang, V. Leung, N. Guizani, and T. Jiang, "D2D big data: content deliveries over wireless device-to-device sharing in large-scale mobile networks," IEEE Wireless Communications, vol. 25, no. 1, pp. 32-38, 2018.

[17] S. Singh and A. Yassine, "Big data mining of energy time series for behavioral analytics and energy consumption forecasting," Energies, vol. 11, no. 2, pp. 452-458, 2018.

[18] S. M. Smith and T. E. Nichols, "Statistical challenges in "big data" human neuroimaging," Neuron, vol. 97, no. 2, pp. 263365, 2018.

[19] K. Yang, Q. Yu, S. Leng, B. Fan, and F. Wu, "Data and energy integrated communication networks for wireless big data," Scientia Sinica, vol. 4, no. 4, pp. 713-723, 2018. 
[20] M. J. Axtell and B. C. Meyers, "Revisiting criteria for plant microRNA annotation in the era of big data," Plant Cell, vol. 30, no. 2, pp. 272-284, 2018.

[21] Y. Qian, X. Liang, Q. Wang et al., "Local rough set: a solution to rough data analysis in big data," International Journal of Approximate Reasoning, vol. 97, no. 4, pp. 38-63, 2018.

[22] M. Huda, A. Maseleno, P. Atmotiyoso et al., "Big data emerging technology: insights into innovative environment for online learning resources," International Journal of Emerging Technologies in Learning, vol. 13, no. 1, pp. 23-25, 2018.

[23] L. Mann, "Left to other peoples' devices? A political economy perspective on the big data revolution in development," Development and Change, vol. 49, no. 1, pp. 3-36, 2018.

[24] M. Asch, T. Moore, R. Badia et al., "Big data and extreme-scale computing: pathways to convergence-toward a shaping strategy for a future software and data ecosystem for scientific inquiry," International Journal of High Performance Computing Applications, vol. 32, no. 4, pp. 435-479, 2018.

[25] Z. Zhang, S. Liu, and B. Niu, "Coordination mechanism of dual-channel closed-loop supply chains considering product quality and return," Journal of Cleaner Production, vol. 248, article 119273, 2020.

[26] Z. Lv, Y. Han, A. K. Singh, G. Manogaran, and H. Lv, “Trustworthiness in industrial IoT systems based on artificial intelligence," IEEE Transactions on Industrial Informatics, vol. 17, pp. 1496-1504, 2020.

[27] J. Lei, A. Bz, A. Sh, C. A. He, and W. A. Zheng, "Upscaling evapotranspiration from the instantaneous to the daily time scale: assessing six methods including an optimized coefficient based on worldwide eddy covariance flux network," Journal of Hydrology, vol. 596, article 126135, 2021.

[28] B. Zhang, D. Xu, Y. Liu, F. Li, J. Cai, and L. Du, "Multi-scale evapotranspiration of summer maize and the controlling meteorological factors in north China," Agricultural and Forest Meteorology, vol. 216, pp. 1-12, 2016.

[29] W. Zhang, Y. Hu, J. Liu et al., "Progress of ethylene action mechanism and its application on plant type formation in crops," Saudi Journal of Biological Sciences, vol. 27, no. 6, pp. 1667-1673, 2020.

[30] X. Han, Z. Wei, B. Zhang, Y. Li, and H. Chen, "Crop evapotranspiration prediction by considering dynamic change of crop coefficient and the precipitation effect in backpropagation neural network model," Journal of Hydrology, vol. 596, no. 3-4, article 126104, 2021. 